\title{
Urinary biomarkers for the prediction of reversibility in acute-on-chronic renal failure
}

\author{
Cathy Choi-Wan Luk ${ }^{\mathrm{a}}$, Kai-Ming Chow ${ }^{\mathrm{a}}$, Jeffrey Sung-Shing Kwok ${ }^{\mathrm{b}}$, Bonnie Ching-Ha Kwan ${ }^{\mathrm{a}}$, \\ Michael Ho-Ming Chan ${ }^{\mathrm{b}}$, Ka-Bik Lai ${ }^{\mathrm{a}}$, Fernand Mac-Moune Lai ${ }^{\mathrm{b}}$, Gang Wang ${ }^{\mathrm{a}}$, \\ Philip Kam-Tao Li ${ }^{\mathrm{a}}$ and Cheuk-Chun Szeto ${ }^{\mathrm{a}, *}$ \\ ${ }^{\mathrm{a}}$ Department of Medicine and Therapeutics, Prince of Wales Hospital, The Chinese University of Hong Kong, \\ Shatin, Hong Kong, China \\ ${ }^{\mathrm{b}}$ Department of Chemical Pathology, Prince of Wales Hospital, The Chinese University of Hong Kong, Shatin, \\ Hong Kong, China \\ ${ }^{\mathrm{c}}$ Department of Anatomical and Cellular Pathology, Prince of Wales Hospital, The Chinese University of Hong \\ Kong, Shatin, Hong Kong, China
}

\begin{abstract}
.
BACKGROUND: There is no reliable clinical test to predict the reversibility of acute-on-chronic renal failure. We study whether urinary biomarkers could be used as a noninvasive prognostic marker in patients with acute-on-chronic renal failure.

METHODS: We studied 39 adult patients with pre-existing chronic renal impairment presenting to us with acute-on-chronic renal failure. Urinary neutrophil gelatinase-associated lipocalin (NGAL) level was measured. The mRNA of kidney injury molecule-1 (KIM-1), interleukin-18 (IL-18), alpha-1-microglobulin ( $\alpha 1 \mathrm{M})$, sodium/hydrogen exchanger-3 (NHE3), beta-2 microglobulin $(\beta 2 \mathrm{M})$, and $\mathrm{N}$-acetyl- $\beta$-D-glucosaminidase (NAG) in urinary sediment were quantified.

RESULTS: Urinary NGAL level significantly correlated with the serum creatinine at presentation $(r=0.762, p<0.0001)$ but not baseline serum creatinine. Urinary sediment $\beta 2 \mathrm{M}$ expression significantly correlated with baseline glomerular filtration rate (GFR) $(r=-0.400, p=0.012)$. Urinary $\alpha 1 \mathrm{M}$ and NHE3 expressions were significantly higher in ischemic acute tubular necrosis than other causes of acute kidney injury ( $p<0.0001$ and $p=0.006$, respectively). Urinary $\alpha 1 \mathrm{M}$ expression significantly correlated with the degree of improvement in renal function $(r=0.387, p=0.026)$, as well as the estimated GFR 6 months later $(r=0.386, p=0.027)$.

CONCLUSION: In patients with acute-on-chronic renal failure, urinary NGAL level correlates with the severity of renal failure, while urinary $\alpha 1 \mathrm{M}$ expression correlates with the degree of renal function recovery. Quantification of urinary $\alpha 1 \mathrm{M}$ mRNA may be developed as an non-invasive tool for risk stratification of this group of patients.
\end{abstract}

Keywords: Acute kidney injury, biomarker, proteinuria

\section{Introduction}

Chronic kidney disease (CKD) is a debilitating and costly public health problem worldwide [1]. In the United States, The number of persons with kidney fail-

\footnotetext{
* Corresponding author: Cheuk-Chun Szeto, Department of Medicine and Therapeutics, Prince of Wales Hospital, The Chinese University of Hong Kong, Shatin, NT, Hong Kong, China. Tel.: +852 2632 3878; Fax: +852 2637 3852; E-mail: ccszeto@ cuhk.edu.hk.
}

ure who are treated with dialysis and transplantation is projected to increase from 340000 in 1999 to 651000 in 2010 [2]. The clinical course of CKD is characterized by progressive decline in renal function [3]. However, transient worsening of renal function, often known as "acute-on-chronic" renal failure, is commonly observed in clinical practice, and the acute loss of renal function may or may not be reversible.

Unfortunately, there is no reliable clinical test to predict the reversibility of acute-on-chronic renal failure. 
Traditionally, the reciprocal of serum creatinine in patients with chronic renal failure shows a linear decline with time [4]. This "reciprocal creatinine plot" has been proposed for the recognition of acceleration of renal function deterioration [4], but the plot does not provide any prognostic information. Similarly, neither urinary biochemistry [5] nor renal ultrasonography [6] could predict the degree of reversibility in CKD patients presenting with apparently acute loss of renal function. In the past decade, a number of urinary biomarkers, such as neutrophil gelatinase-associated lipocalin (NGAL), have been developed for the prediction, diagnosis, risk stratification for patients presenting with acute kidney injury [7-9]. However, these biomarkers have not been tested for the prediction of reversibility in acute-onchronic renal failure.

Recently, the study of messenger RNA (mRNA) expression of target genes in urinary sediment has been suggested as a non-invasive marker of renal damage. The mRNA expression of granzyme and perforin in urinary sediment distinguished patients with acute allograft rejection from those without [10]. The urinary mRNA expression of type 1 T-helper cell cytokines correlated with lupus disease activity and the severity of lupus nephritis $[11,12]$. We have previously reported that urinary expression of transforming growth factor-beta (TGF- $\beta$ ) correlated with renal function and the degree of histological damage in CKD [13], while the expression of hepatocyte growth factor (HGF) was an independent indictor of disease progression [14]. The objective of the present study is to identify urinary mRNA targets that could predict the reversibility of acute-on-chronic renal failure.

\section{Patients and methods}

\subsection{Patient selection}

We recruited 39 consecutive adult patients with pre-existing chronic renal impairment presenting to us with acute-on-chronic renal failure. Pre-existing chronic renal impairment was defined as a baseline estimated glomerular filtration rate (GFR) 15 to $60 \mathrm{ml} / \mathrm{min} / 1.73 \mathrm{~m}^{2}$, i.e. stage 3 or 4 CKD according to the Kidney Disease Outcomes Quality Initiative (K/DOQI) guidelines [15]. We estimated the GFR by the abbreviated Modification of Diet in Renal Disease (MDRD) equation [16]. The acute deterioration in renal function was defined as an increase in serum creatinine by at least 2 -fold, or reduction in the estimated
GFR by $>50 \%$ (i.e. "injury" or "failure" stage of the RIFLE criteria) [17]. Patients with complete anuria was excluded.

After written informed consent, background clinical information, underlying renal diagnosis, and the presence of other comorbid conditions were recorded. A whole stream early morning urine sample was collected. If the patient required urinary catheterization, $200 \mathrm{ml}$ of bag urine was used instead of early morning urine sample.

\subsection{Sample storage}

The urine specimen was centrifuged at 3000-g for 30 minutes at $4{ }^{\circ} \mathrm{C}$. After centrifugation, the sediment was dissolved in RNA lysis buffer and stored at $-80^{\circ} \mathrm{C}$ until RNA extraction (see below). We also saved $10 \mathrm{ml}$ of the urine supernatant, which was mixed with $1 \mathrm{ml}$ of $10 \mathrm{mM}$ Tris buffer, $\mathrm{pH} 8.6$ with $0.05 \%$ Tween 20 and $0.01 \%$ of $\mathrm{NaN}_{3}$ containing protease inhibitors (10 $\mathrm{mM}$ benzamidine, $10 \mathrm{mM}$ aminocaproic acid, $20 \mathrm{mM}$ ethylenediaminetetracetate and aprotinin). This mixture was stored at $-80^{\circ} \mathrm{C}$ until assay.

\subsection{Urinary NGAL}

NGAL level in urinary supernatant was measured by a commercially available ELISA kit (Abbott Laboratories, Longford, Ireland), following manufacturer's instruction. The limit of quantitation was $2 \mathrm{ng} / \mathrm{ml}$; the total coefficient of variation of the assay was $\leqslant 10 \%$. For levels below $10 \mathrm{ng} / \mathrm{ml}$, the test was repeated and the average value was reported.

\subsection{Quantification of $m R N A$}

The methods of RNA extraction from urinary sediment have been described by Li et al. [10]. Briefly, total RNA was extracted by the RNeasy Mini Kit (Qiagen Inc., Canada). All specimens were pre-treated with Deoxyribonuclease. The purity of RNA was confirmed by the relative absorbance at $260 / 280 \mathrm{~nm}$ ratio. The integrity of RNA was tested in random samples by running total RNA in denaturing $1.5 \%$ agarose gel to demonstrate $28 \mathrm{~S}$ and $18 \mathrm{~S}$ rRNA bands.

Around $0.5 \mu \mathrm{g}$ of RNA was reverse transcribed to complementary DNA. Real time quantitative polymerase chain reaction (RT-QPCR) was performed by ABI Prism 7700 Sequence Detector System (Applied Biosystems, Foster City, CA). We quantified the mRNA expression of kidney injury molecule-1 (KIM-1), 
interleukin-18 (IL-18), alpha-1-microglobulin ( $\alpha 1 \mathrm{M})$, sodium/hydrogen exchanger-3 (NHE3), beta-2 microglobulin $(\beta 2 \mathrm{M})$, and $\mathrm{N}$-acetyl- $\beta$-D-glucosaminidase (NAG). This panel of mRNA targets were chosen because of their reported prognostic role in patients with simple acute kidney injury [18]. Taqman primers and probes of each target was purchased from Applied Biosystems. The mRNA expression for each signal was calculated by using the $\Delta \mathrm{Ct}$ procedure according to manufacturer's instruction, with $18 \mathrm{~S}$ rRNA used as the housekeeping gene for normalization amongst samples. All primers and probes were tested with purified DNA as the template in RT-QPCR to ensure that they do not amplify genomic DNA. All results were analyzed by Sequence Detection Software version 1.7 (Applied Biosystems).

\subsection{Clinical management}

All recruited patients were followed for 6 months. Their clinical management was decided by individual physician and not affected by the study. After 6 months, patients were classified into 3 groups according to the degree of renal recovery defined as follows [19]: complete recovery if serum creatinine concentrations fell below $110 \%$ of the baseline; partial recovery if serum creatinine remained above $110 \%$ of the baseline and below $90 \%$ of the serum creatinine at presentation; and no recovery if serum creatinine remains above $90 \%$ of the serum creatinine at presentation, or dialysis dependent.

\subsection{Statistical analysis}

Statistical analysis was performed by SPSS for Windows version 16.0 software (SPSS Inc., Chicago, IL). Data are presented in mean \pm SD unless otherwise specified, and were compared between groups by one way analysis of variance (ANOVA) or Kruskal Wallis test as appropriate. Correlations between urinary mRNA expression and clinical parameters were explored by Spearman's rank correlation coefficient. A $P$ value below 0.05 was considered significant. All probabilities were two-tailed.

\section{Results}

We recruited 39 patients; 9 had pre-existing stage 2, 19 had stage 3 , and 11 had stage 4 CKD. Of these 39 patients, 17 had ischemic acute tubular necrosis (ATN) while 22 had other causes of acute kidney injury (AKI).
Table 1

Baseline clinical and demographic data

\begin{tabular}{lcc}
\hline Diagnosis group & ATN & others \\
\hline No. of patients & 17 & 22 \\
Sex (M:F) & $12: 5$ & $14: 8$ \\
Age (years) & $62.7 \pm 20.5$ & $62.8 \pm 13.0$ \\
Body weight $(\mathrm{kg})$ & $61.5 \pm 12.2$ & $62.3 \pm 10.8$ \\
Body height $(\mathrm{cm})$ & $160.7 \pm 6.8$ & $158.6 \pm 6.2$ \\
Body mass index $\left(\mathrm{kg} / \mathrm{m}^{2}\right)$ & $23.7 \pm 3.7$ & $24.7 \pm 3.6$ \\
Baseline renal function & & \\
$\quad$ Serum creatinine $(\mu \mathrm{mol} / \mathrm{l})$ & $139.4 \pm 76.5$ & $187.5 \pm 116.9$ \\
$\quad$ GFR $\left(\mathrm{ml} / \mathrm{min} / 1.73 \mathrm{~m}^{2}\right)$ & $54.9 \pm 30.9$ & $43.8 \pm 28.1$ \\
Renal function at presentation & & \\
$\quad$ Serum creatinine $(\mu \mathrm{mol} / \mathrm{l})$ & $497.5 \pm 311.2$ & $405.0 \pm 282.9$ \\
$\quad$ GFR (ml/min/ $\left./ .73 \mathrm{~m}^{2}\right)$ & $16.2 \pm 11.6$ & $22.3 \pm 17.7$ \\
\hline
\end{tabular}

ATN, acute tubular necrosis due to an episode of ischemia; GFR, glomerular filtration rate.

Their baseline clinical and demographic information are compared and summarized in Table 1. There was no significant difference in age, baseline renal function, or renal function at presentation between patients with acute tubular necrosis and those with other causes of AKI. There was no significant relation between the age or serum creatinine level at presentation and the stage of pre-existing CKD (details not shown).

\subsection{Urinary NGAL level}

The average urinary NGAL level of the recruited patients was $462.2 \pm 515.9 \mathrm{ng} / \mathrm{ml}$ (range 2.2 to $1500 \mathrm{ng} / \mathrm{ml}$ ). Urinary NGAL level at presentation significantly correlated with the serum creatinine and estimated GFR at presentation $(r=0.762$ and $r=$ -0.740 respectively, $p<0.0001$ for both). In contrast, urinary NGAL level at presentation had only a modest and insignificant correlation with baseline serum creatinine ( $r=0.301, p=0.094)$. There was also no significant difference in urinary NGAL level between patients with ischemic ATN and other causes of AKI $(505.9 \pm 122.6$ vs. $544.6 \pm 140.6 \mathrm{ng} / \mathrm{ml}, p=0.9)$.

\subsection{Urinary $m R N A$ expression}

Amongst the six mRNA targets tested, there were significant internal correlations between the urinary sediment levels of KIM-1, $\alpha 1 \mathrm{M}$ and NHE3 (Table 2). Urinary sediment $\beta 2 \mathrm{M}$ expression significantly correlated with baseline GFR $(r=-0.400, p=0.012)$. Urinary sediment level of other mRNA targets did not correlate with patients' age, baseline renal function, or renal function at presentation (details not shown). Urinary NGAL level had a modest inverse correlation with urinary sediment expression of NHE3 $(r=-0.452$, 
Table 2

Internal correlation between urinary sediment level of mRNA targets

\begin{tabular}{llllll}
\hline & IL-18 & $\alpha 1 \mathrm{M}$ & NHE3 & $\beta 2 \mathrm{M}$ & NAG \\
\hline KIM-1 & $r=0.255$, & $r=0.715$, & $r=0.668$, & $r=-0.183$, & $r=-0.063$, \\
& $p=0.159$ & $p<0.0001$ & $p<0.0001$ & $p=0.317$ & $p=0.732$ \\
IL-18 & & $r=-0.001$, & $r=0.125$, & $r=0.279$, & $r=-0.079$, \\
& & $p=0.999$ & $p=0.468$ & $p=0.090$ & $p=0.637$ \\
$\alpha 1 \mathrm{M}$ & & $r=0.783$, & $r=-0.388$, & $r=-0.015$, \\
& & $p<0.0001$ & $p=0.026$ & $p=0.937$ \\
NHE3 & & & $r=-0.202$, & $r=0.061$, \\
& & & $p=0.239$ & $p=0.723$ \\
$\beta 2 \mathrm{M}$ & & & & $r=-0.126$, \\
& & & & $p=0.444$ \\
\hline
\end{tabular}

(A)

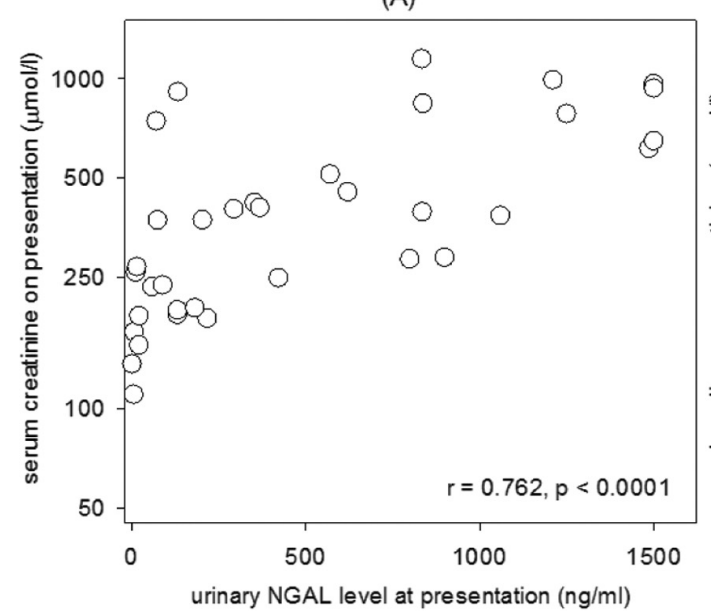

(B)

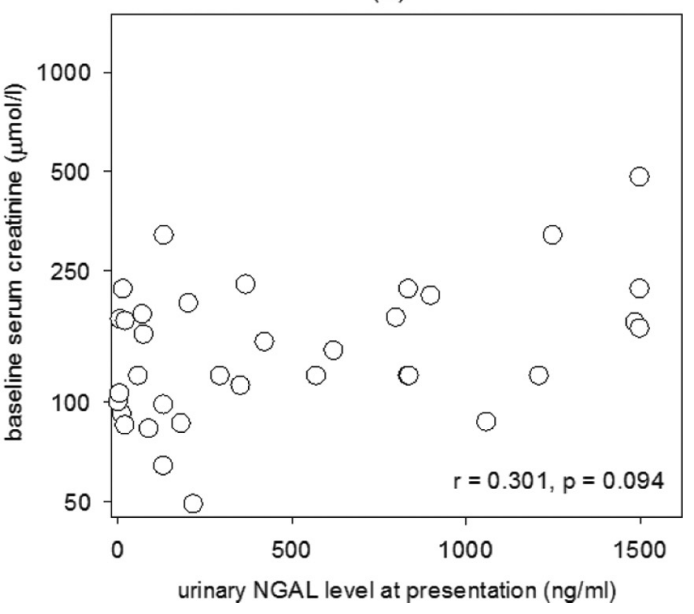

Fig. 1. Relation between urinary neutrophil gelatinase-associated lipocalin (NGAL) level at presentation and (A) serum creatinine at presentation; and (B) baseline serum creatinine level. Data are compared by Spearman's rank correlation coefficient.

$p=0.014$ ) but not other mRNA targets (details not shown).

We compare the urinary sediment mRNA expression between patients with ischemic ATN and other causes of AKI. The result is summarized in Fig. 1. In essence, urinary sediment $\alpha 1 \mathrm{M}$ and NHE3 expressions were significantly higher in ischemic ATN than other causes of AKI ( $p<0.0001$ and $p=0.006$, respectively), while urinary sediment expression of other mRNA targets were similar between ATN and other causes of AKI.

\subsection{Relation with renal recovery}

All were followed for 6 months; 24 had complete recovery of renal function, 7 had partial recovery, and $8 \mathrm{had}$ no recovery. Urinary sediment $\alpha 1 \mathrm{M}$ expression had a modest but statistically significant correlation with the degree of improvement in renal function $(r=$ $0.387, p=0.026)$, as well as the serum creatinine $(r=-0.410, p=0.018)$ and estimated GFR $(r=$ $0.386, p=0.027$ ) 6 months later (Fig. 2). There was no significant interaction between the underlying cause of AKI and urinary sediment $\alpha 1 \mathrm{M}$ expression on the recovery of renal function. The degree of recovery or renal function at 6 months does not correlate with urinary NGAL level or the urinary sediment expression of any other mRNA target (details not shown).

\section{Discussion}

In the present study, we found that in patients with acute-on-chronic renal failure, urinary NGAL level correlates with the severity of renal failure, urinary sediment $\beta 2 \mathrm{M}$ expression correlates with baseline renal function, urinary sediment $\alpha 1 \mathrm{M}$ and NHE3 expressions were significantly higher in ischemic ATN than other causes of AKI, while urinary sediment $\alpha 1 \mathrm{M}$ expression correlates with the degree of renal function recovery. 
(A)

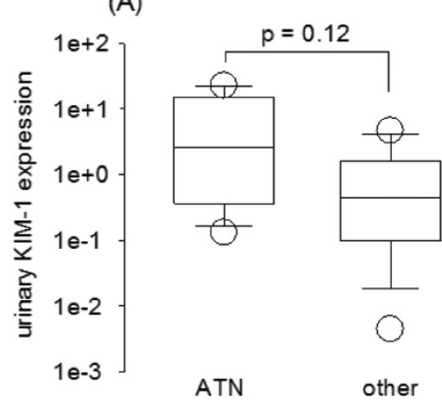

(D)
(B)

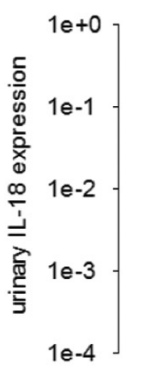

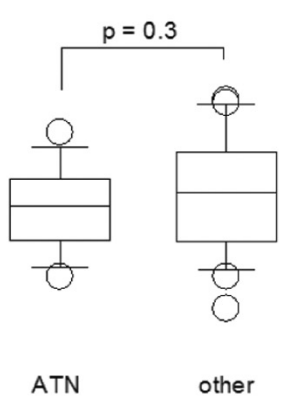

(E)

(C)

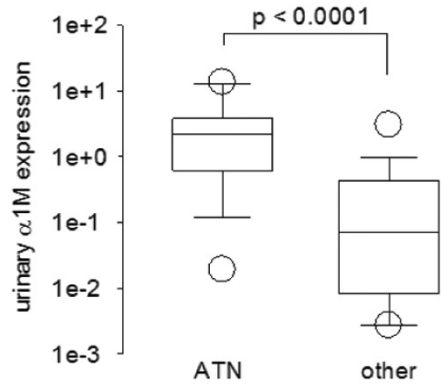

(F)
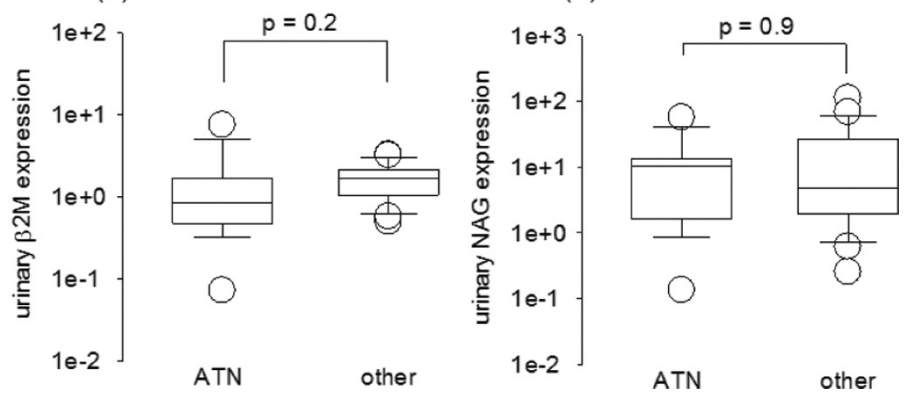

ATN
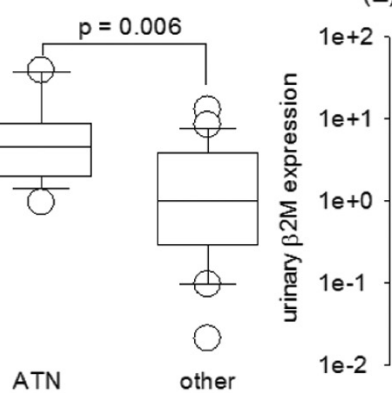

ATN

other

ATN

other

Fig. 2. Comparison of urinary sediment mRNA expression between ischemic acute tubular necrosis (ATN) and other causes of acute kidney injury. (A) kidney injury molecule-1 (KIM-1); (B) interleukin-18 (IL-18); (C) alpha-1-microglobulin ( $\alpha 1 \mathrm{M})$; (D) sodium/hydrogen exchanger-3 (NHE3); (E) beta-2 microglobulin ( $\beta 2 \mathrm{M}$ ); and (F) N-acetyl- $\beta$-D-glucosaminidase (NAG). Data are compared by Mann-Whitney $U$ test; $p$ values are adjusted by the Bonferroni method for multiple comparisons.
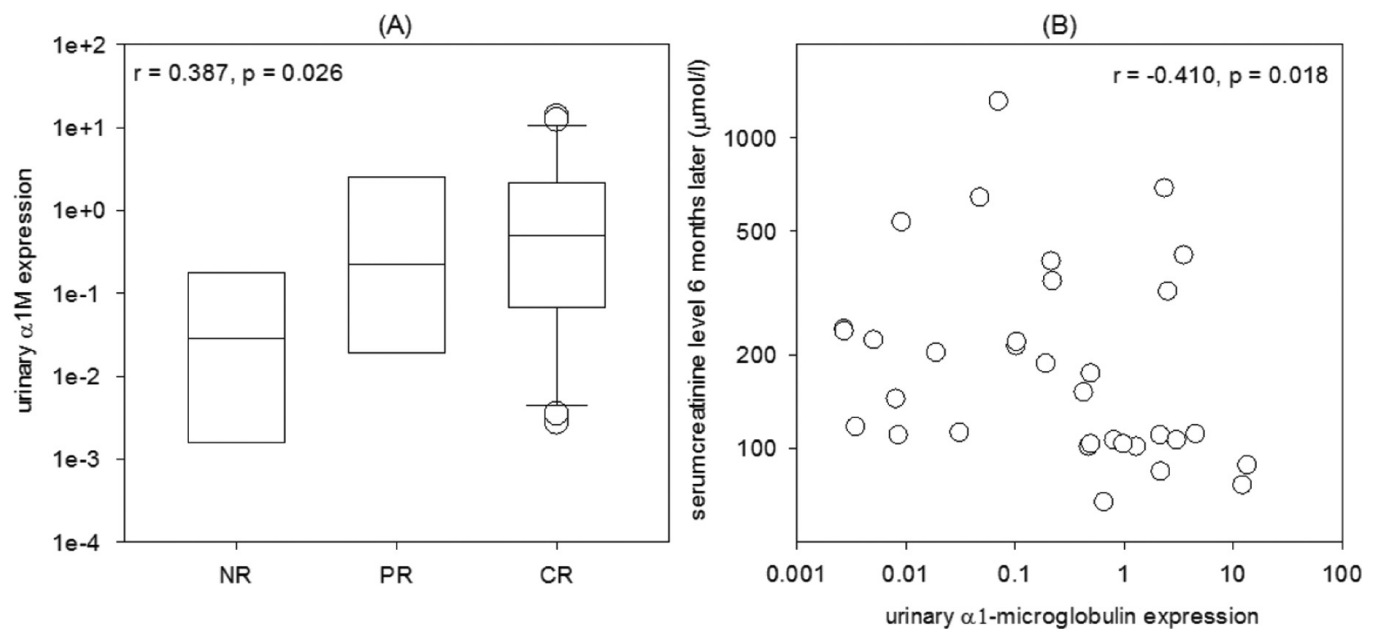

Fig. 3. Relation between urinary alpha-1-microglobulin $(\alpha 1 \mathrm{M})$ expression and (A) degree of renal function recovery; and (B) serum creatinine level 6 months after presentation. Data are compared by Spearman's rank correlation coefficient. (Key: CR, complete recovery; PR, partial recovery; NR, no recovery.)

Our results are essentially consistent with previous reports on pure acute kidney injury. In the present study, we found that urinary NGAL level correlates with the severity of renal failure. It is now recognized that NGAL is one of the fastest up-regulated genes in the early phase of the post-ischemic mouse kidney and the increase in urinary level correlates with the duration of ischemia [20]. A recent analysis also showed that urinary NGAL level had prognostic value for clinical endpoints, such as initiation of dialysis and mortality [21]. Unfortunately, our present study does not have the sufficient sample size to explore this possibility. 
Our observation that urinary sediment $\alpha 1 \mathrm{M}$ expression correlates with the degree of renal function recovery is intriguing. Previous studies on urinary $\alpha 1 \mathrm{M}$ at protein level showed that increased urinary excretion of $\alpha 1 \mathrm{M}$ indicates proximal tubular injury [22], and urinary $\alpha 1 \mathrm{M}$ level is markedly increased during the early post-operative phase in patients subsequently developing AKI [23]. However, it is important to note that circulating $\alpha 1 \mathrm{M}$ is largely produced by hepatocytes [24]; urinary $\alpha 1 \mathrm{M}$ protein comes from glomerular filtration and incomplete proximal tubular reabsorption [24]. Nonetheless, the $\alpha 1$-microglobulin/bikunin precursor (AMBP) gene is also expressed in a wide variety of tissues, including the kidney tubular cells [25]. Previous studies showed that $\alpha 1 \mathrm{M}$ plays an anti-inflammatory role, at least in part by contributing to heme degradation and reducing free radical formation [26-28]. It remains unknown whether these anti-inflammatory property of $\alpha 1 \mathrm{M}$ contribute to the better recovery of renal function.

Contrary to our expectation, we did not find urinary NGAL or IL-18 expression predictive of renal function recovery. In contrast, our previous study in kidney transplant recipients found that urinary NGAL and IL-18 expression are associated with response to antirejection therapy [29]. The discrepancy is probably explained by the fact that cellular rejection is essentially an inflammatory condition, and the severity or reversibility could understandably assessed by urinary NGAL and IL-18 expression. We also previously found that urinary KIM-1 expression correlates with the rate of renal function decline in kidney transplant patients with acute renal dysfunction, irrespective to the kidney pathology [29]. In the present study, our duration of observation was short and we could not determine whether urinary KIM-1 provides the same long-term prognostic information for non-transplant patients with acute-on-chronic renal failure. Because of the limitations in our original study design, we did not test the prognostic value of urinary expression of hepatocyte growth factor (HGF), which is an independent prognostic indictor of CKD without any acute worsening of kidney function [14].

Several limitations of the current study need to be addressed. First, the sample size of 39 was small and the underlying causes of AKI were heterogeneous. We did not analyse the histological features of a small subgroup of patients who underwent kidney biopsy, or perform a subgroup analysis on patients who required temporary dialysis support. Most importantly, we only studied patients who had at least some urine output, and there is a possibility of selection bias due to the exclusion of completely anuric patients.
Second, we have not determined the exact cellular origin of the mRNA in the urine. Examination under phase contrast microscopy showed that in most cases, urinary sediment the are renal tubular cells, urothelial cells, and, to a lesser extent, some inflammatory cells. We believe all these cellular species contribute to the mRNA we detected in the urinary sediment.

In this study, the MDRD formula was used for the estimation of GFR. Since this formula does not adjust for body mass, it tends to be unreliable for obese and grossly malnourished patients. However, we did not find that body mass index of our patients had any influence on the analysis result when being adjusted for as a covariate (details not shown).

In the present study, we did not measure serum NGAL level or compute the urine-to-serum ratio of NGAL, which are shown by recent studies to have prognostic implications [21,30]. Besides NGAL, we did not determine the protein levels of the other biomarkers in the urine. In theory, determination of the respective proteins has the advantage of an easy and reproductive assay, and it also provides strong additional support for our hypothesis. On the other hand, it has also been argued that urinary biomarkers at protein level could represent leaking from the systemic circulation and correlates with the degree of proteinuria rather than local damage [31].

It is also important to note that our present study focus on acute-on-chronic renal failure, and most of our patients had pre-existing moderate to severe renal failure. It remains unknown whether our results could be extrapolated to patients with no pre-existing renal problem and present with pure acute kidney injury. In this respect, it is now increasingly recognized that a considerable proportion of AKI patients with no preexisting CKD has permanent residual kidney damage and some may progress to end stage renal disease later in their life $[32,33]$. Biomarkers that predict the development of permanent kidney damage after AKI recovery is urgently needed.

\section{Acknowledgement}

This study was supported in part by the Chinese University of Hong Kong (CUHK) research accounts 6901031 and 7101215 . The results presented in this paper have not been published previously in whole or part, except in abstract format. All authors declare no conflict of interest. 


\section{References}

[1] Levey AS, Coresh J, Balk E, Kausz AT, Levin A, Steffes MW, Hogg RJ, Perrone RD, Lau J, Eknoyan G, National Kidney Foundation. National Kidney Foundation practice guidelines for chronic kidney disease: evaluation, classification, and stratification. Ann Intern Med 2003; 139: 137-147.

[2] United States Renal Data System. Excerpts from the 2000 U.S. Renal Data System Annual Data Report: Atlas of End Stage Renal Disease in the United States Am J Kidney Dis 2000; 36 : S1-S279.

[3] Remuzzi G, Bertani T. Pathophysiology of progressive nephropathies. N Engl J Med 1996; 339: 1448-1456.

[4] Mitch WE, Walser M, Buffington GA, Lemann J Jr. A simple method of estimating progression of chronic renal failure. Lancet 1976; 2: 1326-1328.

[5] Bagshaw SM, Langenberg C, Bellomo R. Urinary biochemistry and microscopy in septic acute renal failure: a systematic review. Am J Kidney Dis 2006; 48: 695-705.

[6] Keyserling HF, Fielding JR, Mittelstaedt CA. Renal sonography in the intensive care unit: when is it necessary? J Ultrasound Med 2002; 21: 517-520.

[7] Coca SG, Parikh CR. Urinary biomarkers for acute kidney injury: perspectives on translation. Clin J Am Soc Nephrol 2008; 3: 481-490.

[8] Molitoris BA, Melnikov VY, Okusa MD, Himmelfarb J. Technology Insight: biomarker development in acute kidney injury-what can we anticipate? Nat Clin Pract Nephrol 2008; 4: $154-165$.

[9] Nickolas TL, Barasch J, Devarajan P. Biomarkers in acute and chronic kidney disease. Curr Opin Nephrol Hypertens 2008; 17: 127-132.

[10] Li B, Hartono C, Ding R, Sharma VK, Ramaswamy R, Qian B, Serur D, Mouradian J, Schwartz JE, Suthanthiran M. Noninvasive diagnosis of renal-allograft rejection by measurement of messenger RNA for perforin and granzyme B in urine. $\mathrm{N}$ Engl J of Med 2001; 344: 947-954.

[11] Chan RW, Tam LS, Li EK, Lai FM, Chow KM, Lai KB, Li $\mathrm{PK}$, Szeto CC. Inflammatory cytokine gene expression in the urinary sediment of lupus nephritis patients. Arthritis Rheum 2003; 48: 1326-1331.

[12] Chan RW, Lai FM, Li EK, Tam LS, Wong TY, Szeto CY, Li PK, Szeto CC. Messenger RNA expression of chemokine and fibrosing factor in the urinary sediment of patients with lupus nephritis. Arthritis Rheum 2004; 50: 2882-2890.

[13] Szeto CC, Lai KB, Chow KM, Szeto CY, Yip TW, Woo KS, Li PK, Lai FM. Messenger RNA expression of glomerular podocyte markers in the urinary sediment of acquired proteinuric diseases. Clin Chim Acta 2005; 361: 182-190.

[14] Szeto CC, Chow KM, Lai KB, Szeto CY, Chan RW, Kwan BC, Chung KY, Li PK, Lai FM. mRNA expression of target genes in the urinary sediment as a noninvasive prognostic indicator of CKD. Am J Kidney Dis 2006; 47: 578-586.

[15] National Kidney Foundation. K/DOQI clinical practice guidelines for chronic kidney disease: evaluation, classification, and stratification. Am J Kidney Dis 2002; 39 (2 Suppl 1): S1-266.

[16] Ma YC, Zuo L, Chen JH, Luo Q, Yu XQ, Li Y, Xu JS, Huang SM, Wang LN, Huang W, Wang M, Xu GB, Wang HY. Modified glomerular filtration rate estimating equation for Chinese patients with chronic kidney disease. J Am Soc Nephrol 2006; 17: 2937-2944.
[17] Bellomo R. Defining, quantifying, and classifying acute renal failure. Crit Care Clin 2005; 21: 223-237.

[18] Coca SG, Yalavarthy R, Concato J, Parikh CR. Biomarkers for the diagnosis and risk stratification of acute kidney injury: a systematic review. Kidney Int 2008; 73: 1008-1016.

[19] Ali T, Khan I, Simpson W, Prescott G, Townend J, Smith W, Macleod A. Incidence and outcomes in acute kidney injury: a comprehensive population-based study. J Am Soc Nephrol 2007; 18: 1292-1298.

[20] Supavekin S, Zhang W, Kucherlapati R, Kaskel FJ, Moore LC, Devarajan P. Differential gene expression following early renal ischemia/reperfusion. Kidney Int 2003; 63: 1714-1724.

[21] Haase M, Bellomo R, Devarajan P, Schlattmann P, HaaseFielitz A. Accuracy of neutrophil gelatinase-associated lipocalin (NGAL) in diagnosis and prognosis in acute kidney injury: a systematic review and meta-analysis. Am J Kidney Dis 2009; 54: 1012-1024.

[22] Bernard AM, Vyskocil AA, Mahieu P, Lauwerys RR. Assessment of urinary retinol-binding protein as an index of proximal tubular injury. Clin Chem 1987; 33: 775-779.

[23] Ho J, Lucy M, Krokhin O, Hayglass K, Pascoe E, Darroch G, Rush D, Nickerson P, Rigatto C, Reslerova M. Mass spectrometry-based proteomic analysis of urine in acute kidney injury following cardiopulmonary bypass: a nested casecontrol study. Am J Kidney Dis 2009; 53: 584-595.

[24] Penders J, Delanghe JR. Alpha 1-microglobulin: clinical laboratory aspects and applications. Clin Chim Acta 2004; 346: 107-118.

[25] Sánchez D, Martínez S, Lindqvist A, Akerström B, Falkenberg C. Expression of the AMBP gene transcript and its two protein products, alpha(1)-microglobulin and bikunin, in mouse embryogenesis. Mech Dev 2002; 117: 293-298.

[26] Santin M, Cannas M. Collagen-bound alpha 1-microglobulin in normal and healed tissues and its effect on immunocompetent cells. Scand J Immunol 1999; 50: 289-295.

[27] Mendez E, Fernandez-Luna JL, Grubb A, Leyva-Cobian F. Human protein $\mathrm{HC}$ and its IgA complex are inhibitors of neutrophil chemotaxis. Proc Natl Acad Sci USA 1986; 83: 14721475.

[28] Ascenzi P, Bocedi A, Altruda F, Tolosano E, Beringhelli T, Fasano M. Hemoglobin and heme scavenging. IUBMB Life 2005; 57: 749-759.

[29] Szeto CC, Kwan BC, Lai KB, Lai FM, Chow KM, Wang G, Luk CC, Li PK. Urinary expression of kidney injury markers in renal transplant recipients. Clin J Am Soc Nephrol 2010; 5: 2329-2337.

[30] Urbschat A, Obermüller N, Haferkamp A. Biomarkers of kidney injury. Biomarkers 2011; 16 (Suppl 1): S22-30.

[31] Wang G, Szeto CC. Quantification of gene expression in urinary sediment for the study of renal diseases. Nephrology (Carlton) 2007; 12: 494-499.

[32] Coca SG, Singanamala S, Parikh CR. Chronic kidney disease after acute kidney injury: a systematic review and metaanalysis. Kidney Int 2012; 81: 442-448.

[33] Coca SG, Yusuf B, Shlipak MG, Garg AX, Parikh CR. Longterm risk of mortality and other adverse outcomes after acute kidney injury: a systematic review and meta-analysis. Am J Kidney Dis 2009; 53: 961-973. 


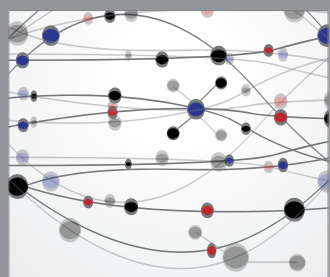

The Scientific World Journal
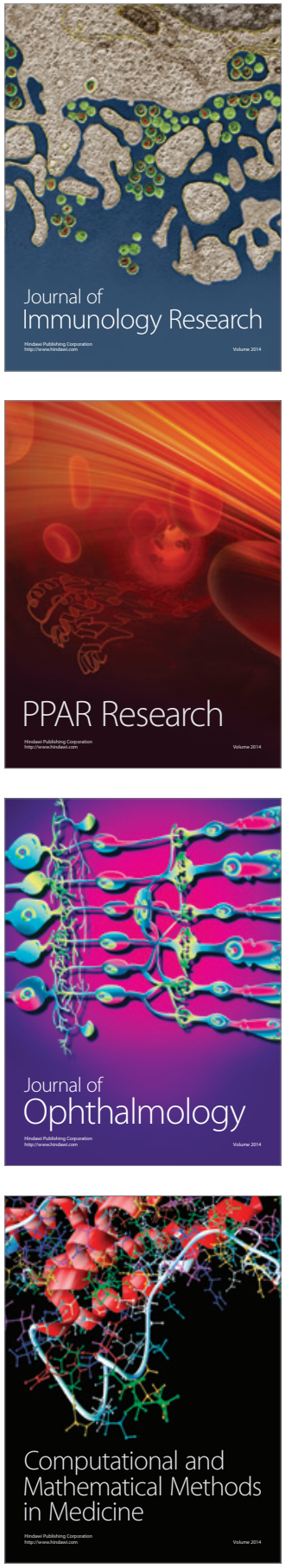

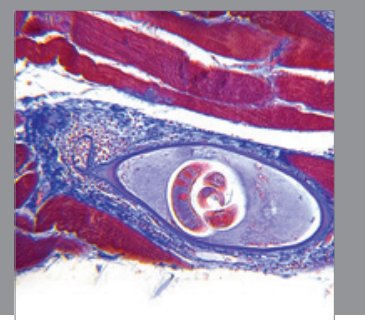

Gastroenterology

Research and Practice
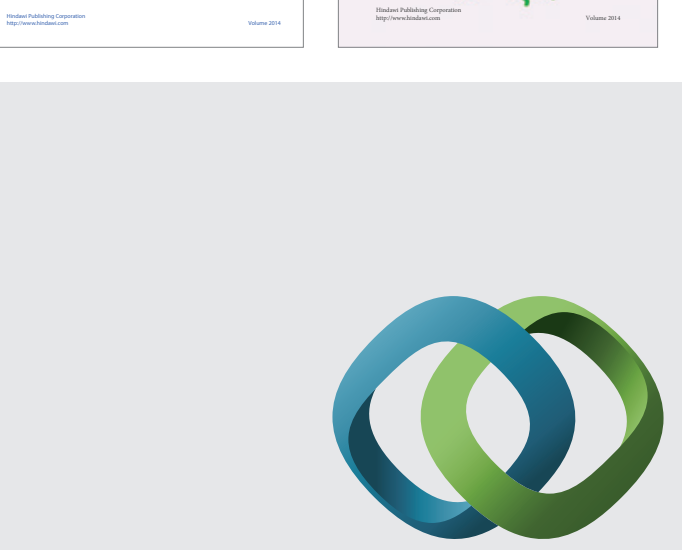

\section{Hindawi}

Submit your manuscripts at

http://www.hindawi.com
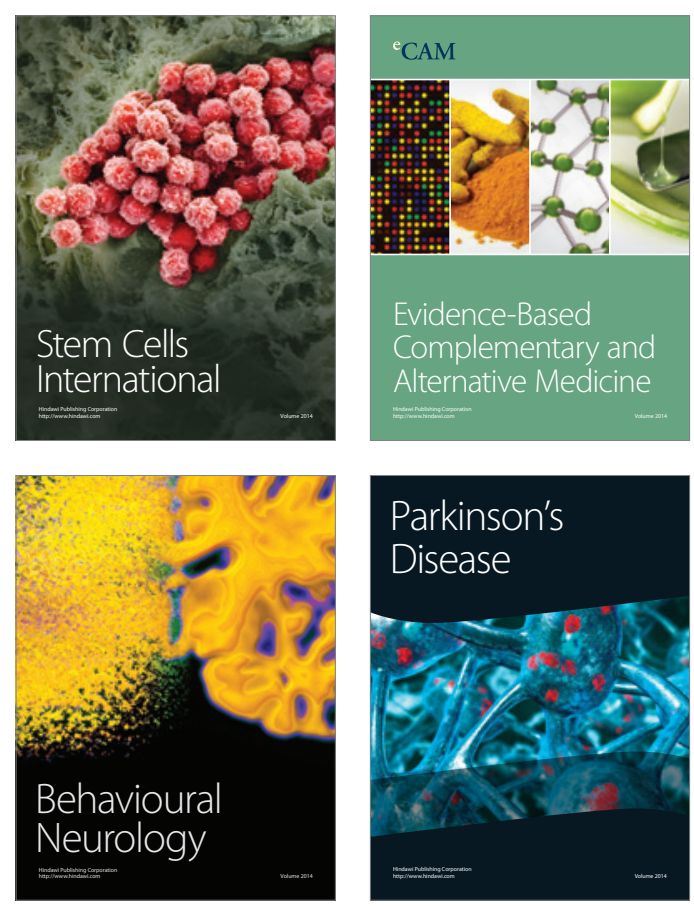

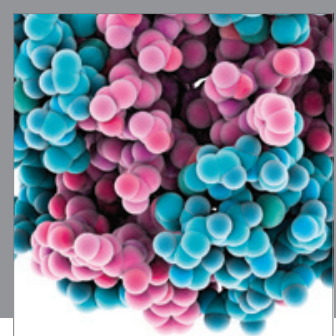

Journal of
Diabetes Research

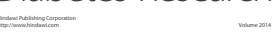

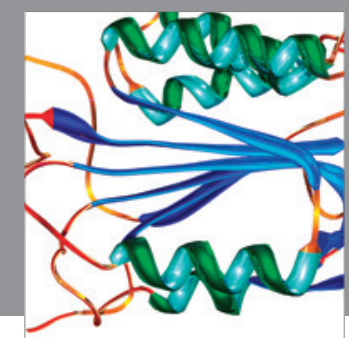

Disease Markers
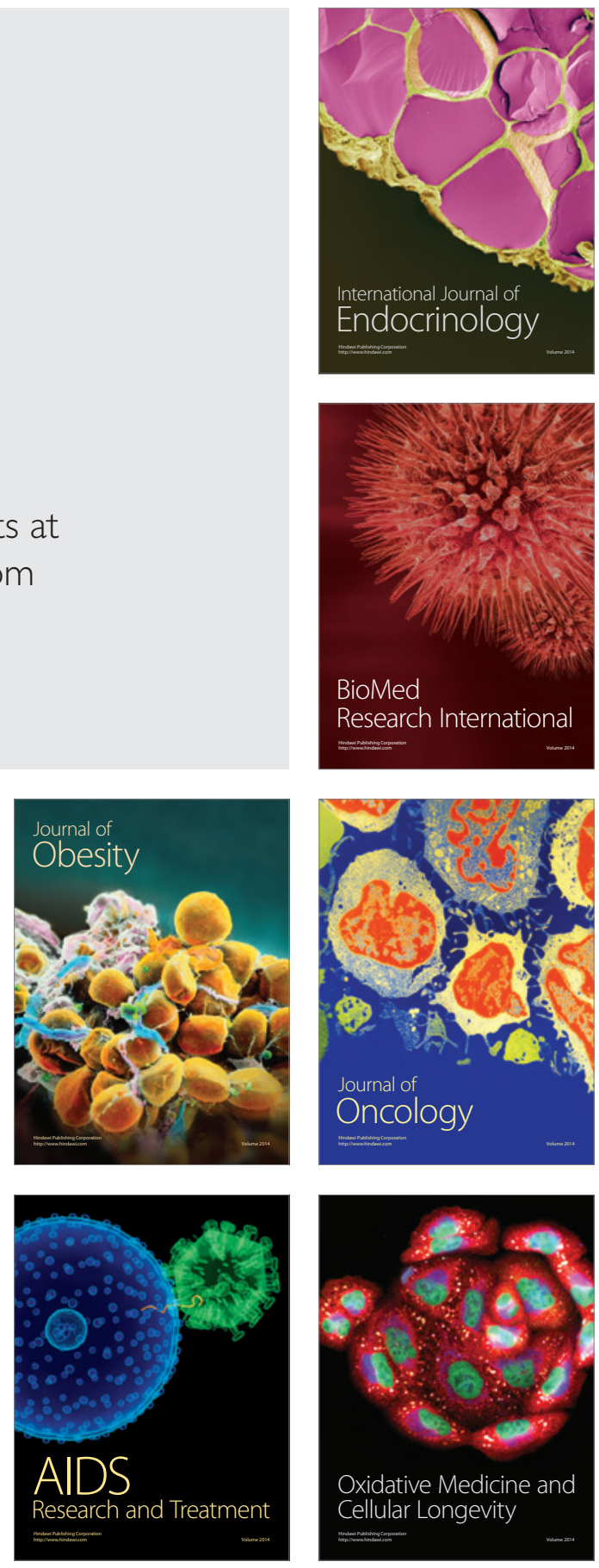